\title{
Propostas de inclusão escolar de crianças com deficiência no município de Holambra, SP: um estudo exploratório*
}

\section{Scholar inclusion purposes for handicapped children in Holambra, SP: an exploratory study}

\author{
Evelien Emmy van Schaik ${ }^{1}$, Maria Inês Britto Brunello
}

\begin{abstract}
VAN SCHAIK, E. E.; BRUNELLO, M. I. B. Propostas de inclusão escolar de crianças com deficiência no município de Holambra-SP: um estudo exploratório. Rev. Ter. Ocup. Univ. São Paulo, v. 23, n. 3, p. 274-282, set./dez. 2012.

RESUMO: O estudo buscou conhecer as propostas e ações das equipes pedagógicas de escolas municipais de ensino básico, do município de Holambra-SP, para efetivar a inclusão escolar de crianças com deficiência e transtornos psíquicos e identificar os principais facilitadores e desafios do processo. A partir de levantamentos das escolas municipais e estaduais de ensino básico do município, foram selecionadas aquelas que tinham crianças com deficiência ou transtornos psíquicos matriculadas. Nelas, buscou-se os profissionais que trabalhavam com crianças nessas condições e realizou-se entrevistas abertas e semi-estruturadas. Os resultados mostram que as equipes pedagógicas vêm construindo propostas de intervenção que respondem à diversidade dos alunos e à heterogeneidade das salas de aula. Apontam também para os facilitadores e desafios que permeiam o processo de inclusão escolar dessa população, tais como: a formação profissional, a importância do apoio de profissionais da saúde e assistência social, bem como recursos e estratégias de ensino desenvolvidas por eles para abarcar todos os alunos. Finalmente, elucida as possíveis contribuições da terapia ocupacional para esse processo. A pesquisa mostrou a importância de conhecer o cotidiano escolar para o que os profissionais implicados com a inclusão escolar, especialmente o terapeuta ocupacional, possam pensar ações efetivas nesse contexto.
\end{abstract}

DESCRITORES: Educação especial; Crianças com deficiência/educação; Mainstreaming (educação); Terapia ocupacional.

\footnotetext{
* Pesquisa apresentada como trabalho de conclusão do curso de terapia ocupacional do Departamento de Fisioterapia, Fonoaudiologia e Terapia Ocupacional da Faculdade de Medicina da Universidade de São Paulo.

1. Graduanda no curso de Terapia Ocupacional do Departamento de Fisioterapia, Fonoaudiologia e Terapia Ocupacional da Faculdade de Medicina da Universidade de São Paulo.

2. Prof $^{\mathrm{a}}$. Dr ${ }^{\mathrm{a}}$. do curso de Terapia Ocupacional do Departamento de Fisioterapia, Fonoaudiologia e Terapia Ocupacional da Faculdade de Medicina da Universidade de São Paulo.

Endereço para correspondência: Departamento de Fisioterapia, Fonoaudiologia e Terapia Ocupacional da FMUSP. Rua Cipotânea, nº 51 Cidade Universitária. São Paulo, SP. CEP: 05360-160. E-mail: vilin.evs@hotmail.com
} 


\section{INTRODUÇÃO}

$\mathrm{O}$ trabalho técnico desenvolvido junto a crianças com deficiência implica em articulação com a inclusão escolar, compreendendo a escola como o lugar privilegiado de encontro com o outro, aprendizagem e trocas sociais de toda criança (BRUNELLO, 2001). Segundo Rocha (2003), inclusão escolar compreende a inserção de crianças com deficiência em escolas regulares, e depende da estruturação das instituições no que diz respeito ao arcabouço físico, à capacitação dos profissionais da educação, materiais adaptados e mudanças no imaginário da comunidade a respeito da pessoa com deficiência, trazendo um novo sentido para a deficiência e para a inclusão social.

Mantoan (2007) sugere que a inclusão escolar requer a ressignificação do papel da escola e da educação, trabalho a ser feito com pais, professores e comunidade. Desvelar e destacar a diversidade humana para compreender o mundo e a cada sujeito singular deve ser a prioridade da educação e objetivo das escolas, e "que seus planos se redefinam para uma educação voltada para a cidadania global, livre de preconceitos, que reconheça e valorize as diferenças" (p. 16).

Historicamente, o desenvolvimento de cuidados e processos educativos destinados às pessoas com deficiência se constituía na segregação dessas pessoas em grandes instituições. A partir do século XX, as tendências da educação inclusiva passam a visar a superação o modelo de segregação, refletir e propor formas de promover a participação social das pessoas com deficiência (BRIANT, 2008).

As grandes instituições destinadas a essa população datam do século XIX, período em que a deficiência foi reconhecida como uma doença, uma anomalia corporal que deveria ser corrigida. Eram espaços normativos e segregacionistas, pois, ao mesmo tempo em que tentavam reabilitar o indivíduo de acordo com a norma social vigente, destinavam-se exclusivamente a essa população, o que restringia suas possibilidades de convívio social e em ambientes diversificados. Este modelo também resultou nas proposições das escolas especiais (MAZZOTI, 2000), que "eram espaços segregados para certas pessoas que a sociedade considerava incapazes para realizarem as mesmas atividades que outras" (BRIANT, 2008, p. 15).

Entretanto, as lutas de pessoas com deficiência, seus familiares, profissionais de saúde, educação, assistência social e outros, respaldados pela Declaração dos Direitos Humanos e do Estatuto da Criança e do Adolescente, geraram posicionamentos como o expresso na Conferência de Salamanca, em 1994, que amplia o significado da expressão "pessoas com necessidades educacionais especiais" e passa a abranger o conjunto de pessoas que, por algum motivo que não se restringia à deficiência, tinham necessidades educacionais especiais (UNESCO, 1994).

Lançada no Brasil em 1996 e atualizada em 2010, a Lei de Diretrizes e Bases da Educação regulamenta o sistema educacional e define os princípios gerais da educação escolar, as finalidades, recursos financeiros, formação e diretrizes para a carreira dos profissionais do setor. Considera a educação especial como "modalidade de educação escolar, oferecida preferencialmente na rede regular de ensino, para educandos portadores de necessidades especiais" (BRASIL, 2010, p. 43) e ressalta que, quando necessário, devem ser implementados equipamentos de apoio especializados para atender às demandas desse grupo (BRASIL, 2010).

Os conceitos sobre educação especial e inclusiva foram aprimorados quanto às exigências e recursos que deveriam existir no processo de constituição do novo modelo de educação direcionado às crianças com necessidades educacionais especiais. Para tanto, a resolução n. 4 do Ministério da Educação e da Cultura, institui, em 02 de outubro de 2009 que

os sistemas de ensino devem matricular os alunos com deficiência, transtornos globais do desenvolvimento e altas habilidades/superdotação nas classes comuns do ensino regular e no Atendimento Educacional Especializado (AEE) (BRASIL. Decreto $n^{\circ} 6.571$, de 02 de outubro de 2009).

Esses documentos são resultados do processo desencadeado pela Declaração Mundial de Educação para Todos, que data de 1990 e traz ao cenário educacional mundial a discussão sobre o acesso e permanência de crianças e jovens com deficiência no ensino regular (WCEFA, 1990).

Ao longo do processo de construção desses documentos, vários programas foram elaborados, como o Programa de Atendimento aos Alunos com Necessidades Educacionais Especiais da rede pública, proposto, em abril de 2002, pela Secretaria de Educação do Estado de São Paulo. Esse documento determina que crianças com necessidades educacionais especiais devem ficar preferencialmente em classes regulares de ensino e que as escolas, estaduais e municipais, devem reconhecer e responder às necessidades educacionais de seus alunos, por meio de currículo adaptado, profissionais capacitados, estratégias de ensino e formação continuada dos profissionais (SÃO PAULO, 2002).

Destaca-se também o Centro de Apoio Pedagógico Especializado (CAPE), programa estadual que oferece 
suporte ao processo de inclusão escolar na rede estadual de ensino e atua no gerenciamento, acompanhamento e suporte às ações regionais de educação especial. Promove ações através de programas diversos, que incluem a formação contínua dos profissionais da rede e outras iniciativas que envolvem parcerias com instituições, universidades e a instâncias sociais diversas (PROGRAMA CAPE, 2001).

No município de São Paulo se pode citar o "Programa Inclui", lançado em 2010 e ainda em vigor, cujo objetivo reside na construção de uma escola pública para todos ou democratização qualitativa da educação, para que a cidade tenha escolas cada vez mais adaptadas e acolhedoras (PROGRAMA INCLUI, 2010). Os exemplos citados visam traçar o panorama da constituição de programas de inclusão escolar no Estado e na Prefeitura do Município de São Paulo.

Observa-se que nesses níveis já são encontrados programas em andamento que priorizam a questão da inclusão escolar de crianças com necessidades educacionais especiais. Porém, encontramos poucos trabalhos que descrevem como a inclusão escolar desses sujeitos tem sido discutida e proposta em outras cidades do estado de São Paulo.

A cidade de Holambra foi escolhida para a realização da pesquisa por ser uma cidade de pequeno porte com área de $66 \mathrm{~km}^{2}$ e 11.299 habitantes; pela sua proximidade com as metrópoles de Campinas e São Paulo, a 40km e 130 km, respectivamente, e pelo seu alto Índice de Desenvolvimento Humano - 0,827. Apresenta 107 pessoas que frequentam a Educação Especial, que compreende alunos de escolas especiais, classes especiais e incluídos na rede regular de ensino (IBGE, 2010). Contribuiu também para a escolha a facilidade de acesso aos documentos e aos profissionais das instituições de ensino.

Dessa forma, esta pesquisa teve o objetivo central de conhecer e identificar as ações e propostas realizadas pelas equipes pedagógicas para a inclusão escolar de crianças com deficiência ou transtornos psíquicos nas escolas municipais de ensino básico - do primeiro ao quinto ano no município de Holambra-SP, a fim de compreender como essas instituições têm respondido e atuado no que se refere à diversidade dos estudantes, ao acesso e acessibilidade às instituições de ensino e à participação de todos os implicados na inclusão escolar de crianças com deficiência e transtornos psíquicos (equipe pedagógica, familiares e outros profissionais, como da saúde e assistência social). Foram objetivos específicos dessa pesquisa a investigação das estratégias de ensino empregadas pela equipe pedagógica para facilitar o trabalho em sala de aula, bem como a delimitação dos principais entraves e desafios desse processo e a investigação de como a terapia ocupacional pode contribuir para a inclusão escolar.

A pesquisa se justifica pela possibilidade de contribuir com a área da terapia ocupacional, uma vez que esta possibilitou conhecer mais de perto o cotidiano escolar e entender sua dinâmica institucional, fundamental para qualquer nova proposição e ação, como para todos os profissionais que trabalham com a inclusão de crianças com deficiência e transtornos psíquicos. Contribuiu também, para aprofundar reflexões e ampliar propostas de intervenção que respondam à inclusão social com qualidade de crianças que se encontram ainda à margem do sistema educacional, além de cooperar com os trabalhos de inclusão escolar realizados no município de Holambra.

Esse estudo teve como finalidade acadêmica a apresentação enquanto Trabalho de Conclusão do Curso de Terapia Ocupacional do Departamento de Fisioterapia, Fonoaudiologia e Terapia Ocupacional da Faculdade de Medicina da Universidade de São Paulo. Foi realizado entre os meses de janeiro de 2011 e julho de 2012, e teve aprovação do Comitê de Ética em Pesquisa da Faculdade de Medicina da Universidade de São Paulo sob protocolo $n^{\circ}$ 258/11, em sessão de 13 de julho de 2011.

\section{PROCEDIMENTOS METODOLÓGICOS}

A pesquisa consiste em um estudo qualitativo e exploratório, e de acordo com os objetivos propostos, buscou-se procedimentos de coleta de dados que pudessem fornecer informações para a construção do panorama geral de constituição da inclusão escolar de crianças com deficiência e com transtornos psíquicos na cidade de Holambra. Para tanto foram desenvolvidas entrevistas com os profissionais da equipe pedagógica que tinham crianças com deficiência ou com transtornos psíquicos em seu cotidiano de trabalho.

Para a seleção dos sujeitos entrevistados, foi realizado levantamento das escolas municipais e estaduais existentes no município, junto à Secretaria Municipal de Educação, que consentiu a realização da pesquisa e o acesso às instituições de ensino e aos profissionais a elas vinculados, mediante Carta de Consentimento. Foram selecionadas as escolas de ensino básico - que servem do primeiro ao quinto ano do ensino fundamental. Dentre as escolas de ensino básico, foram selecionadas aquelas que tinham crianças com deficiência ou transtornos psíquicos matriculadas. Portanto, de 12 escolas existentes no município, 05 eram de ensino básico e essas 05 foram selecionadas.

Nesse contexto, foram levantados os profissionais que tinham crianças com deficiência ou transtornos psíquicos em suas salas de aula - no caso dos professores - e 
em suas escolas - no caso dos coordenadores pedagógicos e diretores. Dessa forma, foram entrevistados 13 professores, quatro coordenadores pedagógicos e dois diretores (os outros dois diretores encontravam-se afastados do cargo).

As entrevistas foram abertas e semi-estruturadas, gravadas após a assinatura do Termo de Consentimento Livre e Esclarecido pelos entrevistados, e guiadas por um roteiro pré-estabelecido que continha pontos de interesse levantados a partir dos da pesquisa e de estudo preliminar de roteiros contidos em outros estudos da mesma natureza. As entrevistas possibilitaram o estabelecimento de relações entre as múltiplas variáveis que interferiam no processo de educar uma criança com necessidades educacionais especiais, visando apreender o que os entrevistados pensavam, sabiam, sentiam, faziam e argumentavam (GIL, 1988; SEVERINO, 2007) sobre sua experiência na educação inclusiva.

Esses pontos abrangiam os seguintes aspectos: estratégias utilizadas pela equipe pedagógica para facilitar a inclusão escolar de crianças com deficiência ou transtorno psíquico; os principais facilitadores e entraves para a aplicação dos programas de inclusão; a existência de recursos de apoio à inclusão escolar de crianças com deficiência e transtornos psíquicos município. Foi realizada uma entrevista-teste com um dos profissionais selecionados para verificar a efetividade e clareza das questões apresentadas.

A transcrição das entrevistas buscou separar as questões trazidas pelos profissionais em eixos temáticos, para facilitar a análise subsequente. Por fim, agrupou-se esses temas em dois grandes grupos: "Entraves e desafios para o processo de inclusão escolar de crianças com deficiência ou transtornos psíquicos no município de Holambra-SP" e "Estratégias, facilitadores e potências para o processo de inclusão escolar de crianças com deficiência ou transtornos psíquicos no município de Holambra-SP”.

\section{RESULTADOS E ANÁLISE}

A inclusão escolar é um processo complexo e multifatorial, dependente da equipe pedagógica, da família, dos equipamentos e recursos do território onde a escola está inserida - incluindo a rede de apoio de profissionais que não sejam especificamente da educação - e da própria criança, suas demandas e objetivos em relação à sua entrada na escola.

\section{Entraves e desafios para o processo de inclusão escolar de crianças com deficiência e transtornos psíquicos no}

município de Holambra, SP.

A maioria dos entrevistados referiu não se sentir preparada para receber uma criança com necessidades educacionais especiais em suas salas de aula, por medo do que essa inclusão possa acarretar no cotidiano de suas aulas, por não saber o que fazer e até onde ir, ou mesmo por desconhecimento das principais questões do aluno. A presença de uma ou mais crianças com alguma deficiência ou transtorno psíquico traz angústias, medo e insegurança sobre como manejar as situações. Cada criança é única, e as necessidades que apresentam também têm caráter singular e envolvem, mais do que o desempenho acadêmico, o desenvolvimento do sujeito como um todo, o que traz novos desafios ao professor e à equipe pedagógica.

Notou-se a falta de formação profissional para o trabalho nessa área, o que trazia medo, angústia e insegurança para os professores que tinham que lidar diariamente com crianças com deficiência ou transtorno psíquico em suas salas de aula. Os entrevistados referiram não ter tido em sua formação acadêmica disciplinas relativas ao assunto, o que os deixava bastante apreensivos.

O professor tem medo porque não está preparado. Então, acredito que seja possível (a inclusão escolar), mas falta orientação teórica, conhecimento. Porque muitas vezes a gente tem dó, quando deveríamos ter respeito. Você tem que saber lidar com aquilo, e nós não sabemos (E1, diretora).

Quando eu fiz faculdade - terminei em 1997 - no currículo já tinha disciplina de Educação Especial. Embora eu não tenha formação específica nisso. $\mathrm{O}$ curso de pedagogia abrangeu a educação especial, mas não de forma destacada, sabe? Fiz uma pós em psicopedagogia, tem me auxiliado. (E1., professora)

A maioria dos entrevistados revelou que só procurou cursos de pós-graduação ou de formação continuada na área da educação inclusiva depois que receberam a notícia de que teriam uma criança com necessidades educacionais especiais em sua sala de aula ou depois de conviver com a criança e notar a necessidade de um novo direcionamento das atividades propostas, para ela ou para turma.

Se a gente vai fazer inclusão aqui, queria que meus professores fossem preparados, que eles pelo menos soubessem a essência da inclusão e por que fazer. Mas mesmo com os cursos, só se aprende de verdade convivendo. (E2, coordenadora).

Aí, fui fazer psicopedagogia, pra entender alguma coisa e poder orientar (...). Fui buscar pessoas que pudessem me ajudar e dar um pouco mais de bagagem. De que 
maneira posso trabalhar com fulano? Que atividades para memorização, sonorização...? (E1, diretora)

A questão da formação profissional também aparece como um fator importante para que os professores possam conhecer melhor suas crianças, considerando que muitas das entrevistadas referiram mais dificuldades para incluir crianças com maiores comprometimentos físicos, intelectuais ou em habilidades sociais. Ainda referiram a dificuldade sensivelmente maior para educar crianças com grandes comprometimentos em habilidades sociais, exemplificando com episódios de agressão aos colegas de classe ou aos profissionais da escola, episódios de recusas à realização das atividades propostas e de crianças que se desorganizavam muito durante o período em que estavam na escola, gritando, fazendo movimentos repetitivos e jogando materiais e móveis no chão quando contrariados.

Há um aspecto que merece destaque: inicialmente a pesquisa buscou colocar as crianças com deficiência no centro do discurso e da reflexão, mas no decorrer da realização das entrevistas, foram encontradas muitas referências a alunos com transtorno psíquico. Tais crianças apresentam comportamentos que desorganizam o grupo como um todo ocasionando situações com as quais os professores têm muita dificuldade em lidar. Agressividade, indisciplina e impulsividade foram citadas como problemas recorrentes.

Uma vez que o processo escolar tem como objetivo o desenvolvimento global do indivíduo, os professores e equipe pedagógica ressaltaram a necessidade de poderem contar com apoio sistemático e rotineiro de equipe de profissionais da saúde e assistência social. Essa forma de funcionamento pode facilitar o aprofundamento das reflexões e práticas, fundamentando o trabalho desenvolvido pela equipe pedagógica, ampliando a motivação do enfrentamento com as situações cotidianas e ajudando a compreender os sujeitos em sua totalidade.

Os entrevistados citaram dificuldades em construir uma rede de suporte integrando profissionais de outras áreas que não da educação, tendo como justificativa a demora para conseguir o encaminhamento, a vagarosa obtenção do retorno da avaliação e das intervenções feitas pelos profissionais. Consequentemente, apontam para a impossibilidade de fazer um trabalho conjunto e integrado, justificado pela sobrecarga desses profissionais. É indicada, pelas entrevistadas, a proposta de uma presença mais próxima desses no ambiente escolar.

Você não tem uma orientação efetiva sobre como trabalhar com o A., você sabe do senso comum: ele se torna agressivo em alguns momentos, tem dificuldades de aprender determinados assuntos, que precisa ser feita uma atividade diferenciada com ele... Mas como proceder, que tipo de atividade aplicar, a gente não tem esse tipo de orientação (...). Você só aprende de verdade convivendo. Por isso é importante esse elo com os profissionais, porque ali no dia-a-dia você tem com quem compartilhar, com quem buscar informações (E2, coordenadora).

Eu sinto falta (da proximidade com esses profissionais) porque você nunca sabe se o que você tá fazendo está condizendo com o que o profissional tá fazendo (E3, professora).

Para suprir a necessidade de busca de informações, compartilhar avanços, discutir as dificuldades e traçar objetivos, os professores entrevistados referem procurar a sua própria equipe - outros professores, coordenação e direção. Esse coletivo indica a importância de um trabalho que agregue diferentes pessoas e pontos de vista, trabalhando por um mesmo objetivo e buscando apoio uns nos outros.

Temos o encaminhamento, o repasse, mas é pouco. O retorno demora muito, o município tem muitos casos, aí o retorno fica demorado mesmo. Eu tenho mais o apoio do pessoal da escola, a equipe às vezes consegue conversar com os profissionais (da saúde, assistência social) e a gente troca bastante (E5, professora).

Foi citada também a importância da presença de um acompanhante dentro da sala de aula para auxiliar a criança que tenha mais dificuldades decorrentes da deficiência ou do transtorno psíquico, seja para acompanhá-lo nas atividades pedagógicas, na higiene pessoal e alimentação ou somente para dar suporte ao professor. É apontado pelos professores que todas as crianças têm suas particularidades, mas que muitas vezes não é possível dar a devida atenção a cada uma delas em função do número excessivo de alunos em sala. As entrevistadas deixam evidente em suas falas que quando existe um auxiliar que esteja mais próximo das questões das crianças com deficiência ou algum transtorno psíquico dentro de sala de aula, é possível que se tenha uma divisão de responsabilidades, apoio mútuo e desenvolvimento de trabalhos conjuntos.

Se a gente tem alunos com diversidades de inclusão, se eles possuem um laudo, é porque eles têm algo a mais, né? Tem que ter esse acompanhamento, é uma coisa mais próxima, eu vou intervindo, e ela (a acompanhante) vai intervindo também. (...) Se eu não 'tiver' isso, fica humanamente impossível (E4, professora). 
Como a estagiária estava com ele desde o ano passado, ela me falava o que ele queria dizer, aí eu conseguia me comunicar melhor com ele (E8, professora).

2. Estratégias, facilitadores e potências para o processo de inclusão escolar de crianças com deficiência ou transtornos psíquicos no município de Holambra-SP

Apesar das angústias, entraves e desafios que a presença de uma criança com deficiência ou transtorno psíquico traz para o cotidiano escolar, professores e sua equipe pedagógica encontram soluções e estratégias para lidar com as situações que emergem, refletem sobre suas práticas e buscam recursos para incluí-las. As pessoas entrevistadas referem que os materiais que essas crianças utilizam em sala de aula é o mesmo dos demais alunos, mas que as estratégias para trabalhá-los se dá de forma diferenciada.

De acordo com algumas entrevistadas, na medida do possível, as atividades são feitas em conjunto com toda a turma, mas houve um consenso de que em disciplinas específicas como português e matemática, fossem oferecidas individualmente ou em duplas. O trabalho em duplas foi bastante citado pelas professoras que têm alguma criança com necessidades educacionais especiais em sua turma, no sentido de unir aqueles que têm mais facilidade para determinado conteúdo ou habilidade e aquele que tem menos facilidade, na tentativa de que um ajude o outro e que possam desenvolver a atividade de forma compartilhada, abrindo espaço para o desenvolvimento de ambos e para o fortalecimento das relações entre as crianças.

Além da estratégia do trabalho em duplas ou grupos, alguns professores referem inicialmente trabalhar mais individualmente com a criança, para reconhecer suas habilidades e dificuldades e auxiliá-lo quando apresentar problemas na realização de alguma atividade. Segundo uma das entrevistadas, a estratégia utilizada para ensinar determinado conhecimento era modificar a didática de acordo com o limite do aluno. Outra ressalta que é importante deixar que a criança tente fazer a atividade e que o professor entre só posteriormente, não falando como deve ser feita, mas perguntando como eles acham que devem fazer e procurando estimulá-los a pensar a respeito.

Então, eu comecei trabalhando com eles individualmente, para conhecê-los melhor. Quando vi que alguns tinham uma dificuldade maior, fui montando duplas; aquele que tinha uma dificuldade maior ficava com aquele que sabia mais, por exemplo. A cada final de mês, eles tinham a oportunidade de escolher com quem formariam as duplas no próximo mês. (...) Geralmente, aqueles que não conseguiam escrever, era o que eu pedia para escrever. Aquele que sabia, ia orientando o amigo 'olha, é com tal letrinha, agora vai o ponto, agora muda de linha' (E10, professora).

Em relação às atividades realizadas pelas crianças com deficiência ou transtorno psíquico, alguns entrevistados trouxeram que, muitas vezes, é importante exigir menos em relação ao produto, atentando mais ao processo daquilo que se produz, para que se sintam mais seguras e capazes para realizarem as atividades. No contexto de uma atividade direcionada para a sala toda, um dos recursos utilizados é adaptar a atividade do aluno com deficiência ou transtorno psíquico para um grau de dificuldade menor, mas que siga o mesmo formato e conteúdo da atividade da sala. Essas atividades podem integrar o caderno da criança, cuja função é, para algumas professoras, registrar as atividades que foram feitas, os avanços e as dificuldades, sistematizando as informações e acompanhando a criança por toda a sua trajetória escolar.

Além das estratégias de trabalho que professores adotam em suas salas de aula para otimizar o ensinoaprendizagem de crianças com deficiência ou com transtorno psíquico, os entrevistados apontaram diversos recursos para enriquecer a experiência da criança com relação às atividades propostas em sala de aula. Sempre que possível, os professores utilizam recursos para trazer a teoria à prática, como alfabetos móveis, material dourado, experimentos, passeios e atividades artísticas para tornar o aprendizado mais lúdico e interessante.

Outros recursos utilizados pelos professores são: o método fônico - aquele em que o texto é apresentado à criança de modo gradual e com complexidade crescente e à medida que a criança for adquirindo uma boa habilidade de fazer correspondências entre os fonemas (sons) e os grafemas (letras) (CAPOVILLA, 2007) -, a memorização, o envio de atividades de reforço para serem feitas em casa com os pais, o uso do tempo da aula extra do aluno para ter um período de trabalho direcionado e o uso de outras formas de explicar a atividade (ex.: fornecendo um modelo de como ela deve ser feita).

Também foram citadas as provas com alternativas ou com respostas orais, utilizadas para avaliar aqueles que têm dificuldade para escrever. O uso de figuras para indicar a rotina dos alunos e identificar os espaços da escola têm surtido bons resultados para os professores. Ressalta-se a opinião de uma das professoras, sobre as diferentes vias de aprendizado da criança: "Eu aprendi que cada aluno aprende de um jeito, um aprende vendo, o outro ouvindo, o outro só se tocar" (E7, professora). 
Entender que cada aluno aprende de uma maneira é reconhecer e legitimar a sua singularidade e potência, e investir na relação com a criança indica o desejo de conhecêla em suas especificidades e buscar canais de comunicação possíveis. Esse vínculo possibilita um entendimento real da necessidade da criança e de sua maneira de estar no mundo, abrindo espaço para a criação de recursos para o manejo de situações ou na forma como se lida com a criança, como algumas entrevistadas trouxeram:

A expressão facial é muito importante pra ele. Quando quero mostrar que estou brava, faço uma cara bem brava mesmo. Quando quero mostrar que estou feliz, exagero no sorriso. Isso facilita nossa comunicação (E3, coordenadora).

Eu percebi que se eu antecipo pra ele o que vai acontecer, explicando que vamos sair para o recreio e que lá vai ter barulho e mais gente circulando, ele não estranha tanto (E3, professora).

Compreendendo todos os alunos como cooperadores do processo de inclusão escolar de crianças com deficiência ou transtorno psíquico, algumas entrevistadas referiram utilizar livros paradidáticos e dinâmicas para trabalhar aspectos como a própria deficiência ou o transtorno psíquico, o respeito às diferenças, a cooperação, a humildade e a amizade. Trazem que esses trabalhos podem ser desenvolvidos com a sala toda e que melhora significativamente a relação entre as crianças e professores e das crianças com os conteúdos a serem passados.

Omote (2006) refere que a aprendizagem produzida a partir do convívio produtivo com a diversidade é essencial para a formação de gerações mais qualificadas para a promoção da equidade e justiça social. Nesse sentido, a escola é lugar privilegiado - e talvez único - para a promoção desse encontro e convívio.

Os resultados obtidos nessa pesquisa mostraram que apesar das dificuldades, as equipes pedagógicas vêm buscando caminhos para manejar salas de aula heterogêneas, construindo propostas e ações que fazem da inclusão escolar de crianças com deficiência ou com transtornos psíquicos uma realidade que, a despeito dos desafios, vem se mostrando possível no município de Holambra-SP. Também foram apontados inúmeros recursos para as eventuais dificuldades que surgem desse processo, como o apoio da equipe pedagógica e o compartilhamento de experiências, a busca por cursos de formação e as tentativas de contato com profissionais de outras áreas, que não a da educação.

\section{Considerações sobre a possivel atuação do terapeuta}

ocupacional no processo de inclusão escolar de crianças com deficiência ou transtornos psíquicos.

O terapeuta ocupacional pode contribuir para a educação inclusiva, repensando novas formas de lidar com o cotidiano escolar que tem em seu grupo crianças com deficiência e/ou TGDs. Autores como Jurdi (2004) e Costabile e Brunello (2005), resgatados por Rocha (2007), propõem ações no contexto escolar a partir de reflexões sobre o cotidiano e possibilidades de ações grupais e lúdicas junto aos educadores e crianças. Objetiva-se intervir no espaço escolar e em suas relações, atentando aos significados atribuídos às atividades e da superação das dificuldades relacionais, ajudando na superação das dificuldades decorrentes do convívio com a diversidade.

Nessa perspectiva, o terapeuta ocupacional contribui para a desmistificação e o conhecimento da deficiência e do transtorno psíquico, por meio de suporte itinerante, estudos de caso, cursos teórico-práticos, discussões sobre flexibilização curricular e elaboração das principais questões relacionadas a esse assunto.

No trabalho dirigido às crianças com deficiência ou transtorno psíquico, tecnologias específicas podem facilitar o deslocamento e o acesso a diferentes espaços escolares, bem como a adequação de material didático, adaptação das atividades e a ampliação de novas formas de participação no grupo social (ROCHA, 2003; ROCHA, 2007).

No que se refere à família e à comunidade, o terapeuta ocupacional pode facilitar a criação de encontros ou organização de grupos que possam discutir questões relacionadas à inserção da criança com deficiência ou transtorno psíquico no processo educativo (ROCHA, 2007). Por ser a grande colaboradora para o desenvolvimento da criança e por ser desejável que caminhe junto com a escola, a família é grande colaboradora do processo de inclusão, e é fundamental um diálogo entre escola e familiares (COSTABILE; BRUNELLO, 2005).

Assim, as ações da terapia ocupacional no espaço escolar compreendem diversos atores e recursos e são meios para a ampliação de diálogos e possibilidades de participação social.

Através delas (das ações), os medos, dificuldades, os preconceitos e as idéias supersticiosas podem ser reveladas e desmontadas, (...) há a possibilidade de construir novos sentidos, significados. (...) Nenhuma ação é desvinculada de emoções, afetos. E é através desses sentimentos que outras possibilidades relacionais se constituem (ROCHA, 2003, p. 77). 


\section{CONSIDERAÇÕES FINAIS}

Tendo em vista a multiplicidade de fatores que determinam a inclusão escolar de crianças com deficiência e transtorno psíquico, é importante ressaltar que essa pesquisa não esgota o assunto. No entanto, explicita o processo de inclusão escolar na cidade de Holambra, SP segundo a ótica de seus principais atores: a equipe pedagógica, ressaltando a importância da atenção e validação desses discursos, que trazem os principais facilitadores e entraves que encontram nesse trabalho. A partir daí, é possível pensar em estratégias e propostas de ações compartilhadas para efetivar a educação inclusiva.

Enfim é importante ressaltar a importância da aproximação dos profissionais implicados no processo de inclusão escolar, especialmente os terapeutas ocupacionais, aos cotidianos escolares, para que se possa entender as ações referentes à inclusão de crianças com deficiência em classes regulares, conhecer os desafios com os quais se deparam a equipe pedagógica e para poder refletir como o profissional pode contribuir com o planejamento e intervenções que favoreçam a inclusão dessas crianças.

Ainda há muito a fazer no sentido de colaborar com a efetiva inclusão de crianças que se encontram, ainda, à margem do processo de escolarização, e os objetivos só poderão ser atingidos se forem pensados coletivamente, implicando profissionais de diferentes campos do conhecimento, familiares, secretarias da saúde e educação e comunidade em geral nessa complexa, mas não impossível, tarefa.

VAN SCHAIK, E. E.; BRUNELLO, M. I. B. Scholar inclusion purposes for handicapped children in Holambra-SP: an exploratory study. Rev. Ter. Ocup. Univ. São Paulo, v. 23, n. 3, p. 274-82, set./dez. 2012.

\begin{abstract}
This paper sought to know the purposes and actions of pedagogic teams from municipal primary schools, from Holambra-SP, to effecting the scholar inclusion of handicapped children or those who has psychological disorders. It also sought the main elements that make this task easier or harder. A survey of the municipal and state schools was made, and among them, it was selected the primary schools which had handicapped children or those with psychological disorders. Among these schools, the professionals who had children in those conditions in their classrooms were sought, and it was realized opened and semi-structured interviews. The results point out to interventions that respond the children diversity and the heterogeneity of the classrooms. They also point out the elements that make the process easier or harder, such as the training, the importance of support of health and social professionals, and teaching strategies developed by them to encompass all the students. The research indicated the importance of knowing the scholar routine for professionals who take part in the Scholar Inclusion process, specifically the occupational therapist; in that way, it could be thought effective actions in this context.
\end{abstract}

KEYWORDS: Education, special; Disabled children/education; Mainstreaming (education); Occupational therapy.

\title{
REFERÊNCIAS
}

CAPOVIlla, A. G. S.; CAPOVIlla, F. C. Alfabetização: método fônico. 4a ed. São Paulo: Memnon, 2007.

BRASIL. Resolução $n^{0} 4$ MEC CNE/CEB de 2 de outubro de 2009. Institui diretrizes operacionais para o atendimento educacional especializado na educação básica, modalidade educação especial. Brasília, 2009.

BRASIL. Lei de diretrizes e bases da educação nacional. 5a ed. Brasília: Câmara dos Deputados, Coordenação Edições Câmara, 2010 .

BRIANT, M. E. P. A inclusão de crianças com deficiência na escola regular na região do Butantã: conhecendo estratégias e ações. São Paulo, 2008. Dissertação (mestrado em ciências) Faculdade de Medicina, Universidade de São Paulo

BRUNELLO, M. I. B. Ser lúdico: promovendo a qualidade de vida na infância com deficiência. São Paulo, 2001. Tese (doutorado) Instituto de Psicologia, Universidade de São Paulo.

COSTABILE, C.; BRUNELLO, M. I. B. Repercussões da inclusão escolar sobre o cotidiano das crianças com deficiência: um estudo de caso a partir do relato das famílias. Rev. Ter. Ocup. Univ. São Paulo, v. 16, n. 3, p. 124-130, 2005. 
DECLARAÇÃO DE SALAMANCA: sobre princípios, políticas e práticas na área das necessidades educativas especiais. 1994. Disponível em: < http://portal.mec.gov.br/seesp/arquivos/pdf/ salamanca.pdf $>$. Acesso em: 20/03/2011.

GIL, A. C. Como elaborar projetos de pesquisa. São Paulo: Atlas, 1988. p. 92-96.

IBGE. Instituto Brasileiro de Geografia e Estatística. Censo demográfico do município de Holambra-SP. 2010. Disponível em: http://www.ibge.gov.br/cidadesat/link.php?codmun=351905. Acesso em: 23/01/2013.

JURDI, A. P. S. Terapia ocupacional e propostas de intervenção na rede pública de ensino. Rev. Ter. Ocup. Univ. São Paulo, v. 15, n. 1, p. 26-32, 2004.

MANTOAN, M. T. E. Inclusão escolar: o que é? Por quê? Como fazer? 2a ed.São Paulo: Moderna, 2007.

MAZZOTA, M. J. S.; SOUZA, S. M. Z. Inclusão escolar e educação especial: considerações sobre a política educacional brasileira. Rev. Estilos Clínica, n. 9, p. 96-108, 2000.

OMOTE, S. Inclusão e a questão das diferenças na educação. Rev. Perspectiva, v. 24, n. esp., p. 251-272, 2006.
PROGRAMA CAPE. (Estado). São Paulo. Disponível em: <http:// cape.edunet.sp.gov.br/cape_arquivos/cape22.asp>. Acesso em: 21/04/2011.

PROGRAMA INCLUI. São Paulo. Disponível em: <http:// portalsme.prefeitura.sp.gov.br/Anonimo/EdEsp/apresentacao.as px?MenuID=167\&MenuIDAberto=162>. Acesso em: 21/04/2011.

ROCH A, E. F. Reflexões sobre as possíveis contribuições da terapia ocupacional em processos de inclusão escolar. Rev. Ter. Ocup. Univ. São Paulo, v. 14, n. 2, p. 77-8, 2003.

ROCHA, E. F. A terapia ocupacional e as ações na educação. Rev. Ter. Ocup. Univ. São Paulo, v. 18, n. 3, p. 122-127, 2007.

SÃO PAULO (Estado). Resolução $n^{\circ} 61$ de 05 de abril de 2002: sobre ações referentes ao Programa de Inclusão Escolar. Disponível em: <http://lise.edunet.sp.gov.br/sislegis/detresol. asp?strAto $=200204050061>$. Acesso em: 21/04/2011.

SEVERINO, A. J. Metodologia do trabalho científico. 23a ed. São Paulo: Cortez, 2007. p. 117-126.

WCEFA - CONFERÊNCIA MUNDIAL DE EDUCAÇÃO PARA TODOS. Declaração mundial sobre educação para todos e Plano de ação para satisfazer as necessidades básicas de aprendizagem. Jomtien, Tailândia: mar. 1990. 